\title{
Does the Modern Lifestyle Favor the Development of Cervical Cancer?
}

\author{
Maksim Valencic \\ University Hospital Rijeka, Rijeka, Croatia \\ Email: mvalenc82@gmail.com
}

Received 27 September 2015; accepted 13 October 2015; published 19 October 2015

Copyright (C) 2015 by author and OALib.

This work is licensed under the Creative Commons Attribution International License (CC BY). http://creativecommons.org/licenses/by/4.0/

(c) (i) Open Access

\begin{abstract}
Persistent infection with a high-risk human papillomavirus (HRHPV) is generally accepted as a necessary cause of cervical cancer. Modern lifestyle may represent the most influential factor considering persistent genital human papillomavirus (HPV) infection in women. Due to the contemporary clothing and use of toilet bowl, the female micturition is usually performed in sitting position with fully adducted thighs. The resistance to the urine flow due to clenched Labia maiora and Labia minora and capillary pressure among the folded walls of the vagina may cause an abnormal ascension of the urine into the vagina. Urine is an excellent cultivating medium for many microorganisms, including HPV. Education to adequate way of micturition in young girls might be a simple way to significantly reduce the likelihood for a persistent HRHPV infection, by eliminating conditions suitable for growth of virus.
\end{abstract}

\section{Keywords}

Modern Lifestyle, Human Papillomavirus, Cervical Cancer

Subject Area: Gynecology \& Obstetrics

\section{Introduction}

Cervical cancer is the second most common cancer in women worldwide. There are about 60,000 newly detected cases and 30,000 deaths annually in Europe [1]. About 50\% are diagnosed in women between 35 and 55 years of age. Cervical cancer is one of few malignancies with identified etiological factor and known way of development. Sex at a young age, multiple sexual partners, promiscuous male partners, and history of sexually transmitted diseases are major risk factors. Persistent infection with a HRHPV is generally accepted as a necessary cause of cervical cancer [2]. This virus is present in more than $99.7 \%$ of cases of squamous-cell carcinoma of the cervix, and the remaining $0.3 \%$ may be associated with unknown type of HPV [3] [4]. Population-based cervical screening programmes have been shown to be effective in reducing morbidity and mortality from cer- 
vical cancer [5]. High parity increases the risk of squamous-cell carcinoma of the cervix among HPV-positive women. A general decline in parity might therefore partly explain the reduction in cervical cancer recently seen in most countries [6]. Chronic genital infections, hormonal and immunological alterations, other sexually transmitted diseases, contraceptives and smoking are other important factors for the development of this neoplasm [7]. It was estimated that the 2004 direct medical costs associated with HPV infection and treatment approached $\$ 4$ billion in the United States [8]. Attempts of primary prevention of cervical cancer through reduction of HPV infections by propagation of proper sexual behaviour and use of condoms have limited efficacy. At present the most effective forms of cervical cancer primary prevention are prophylactic vaccines [9].

The question is whether modern habits as a result of the modern lifestyle can favor a persistent HPV infection and lead to an overt cervical carcinoma.

\section{Hypothesis}

My hypothesis is that modern lifestyle may represent the most influential factor considering persistent genital HPV infection in women. For many thousand years women have been urinating in a chrouched position with their thighs spread. In this position the external urethral orifice was free and the urine flow was unobstructed. On the modern toilet bowl woman take their pants and under wear down to the knees and urinate in sitting position, with fully adducted thighs. It is the worst possible voiding position in women. Depending on body mass index the distance from the urethral orifice to the free space is in this position about $2-8 \mathrm{~cm}$. There is not only the resistance of the clenched Labia maiora and Labia minora to the urine outflow that causes urine leakage into the vagina, but the capillary pressure between the folded walls of the vagina also favors the ascent of urine in the vagina. In seldom extreme cases, as in a 12-year-old female patient with urinary pseudo incontinence due to an urocolpos, shown in Figure 1, the vagina can be totally filled with urine. Following the advice to widely spread the thighs during voiding the girl became dry.

Urine is an excellent cultivating medium for microorganisms, including HPV. Asymptomaticbacteriuriain womenis mostlythe consequence ofa secondary contaminationof urine with vaginal bacteria. Modern women are usually carefull in propper genital hygiene, most of them generally taking a shower and only rarely abathein a tub.

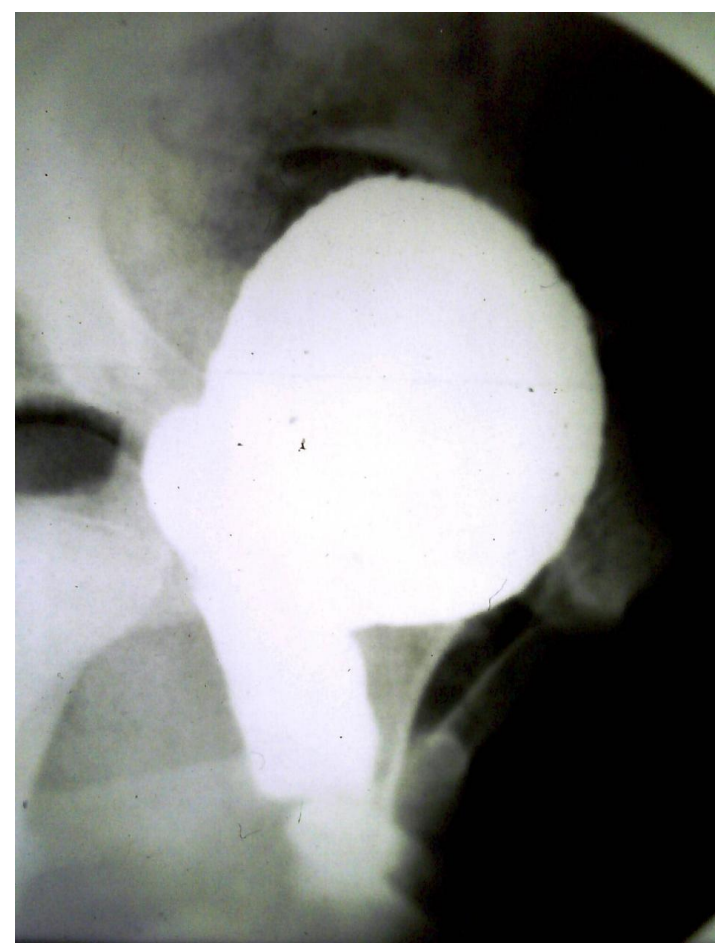

Figure 1. Mictionscystourethrography of a 12-year-old girl with urocolpos and urinary pseudoincontinence. 
Most common factors associated with the presence of highrisk HPV in men include lack of circumcision, younger age, more lifetime sex partners, higher frequency of intercourse (especially with prostitutes), and history of intercourse without condoms. These men place their current female sex partners at greater risk for cervical carcinoma caused by transmission of HPV infection. The degree of genital hygiene, level of education, and smoking status in both male and female partners may also have a role in HPV transmission and survival [10]. Lack of circumcision means the presence of awetchamberunder theforeskin that favors HPV growth. Most commonly isolated in men are HPV types 6 and 11, to which are related approximately $90 \%$ of condyloma acuminata. In resistent or repeated condyloma acuminata a circumcision is performed with the goal to achieve a dry condition of the glans penis toeliminate conditions suitable for growth of HPV.

Some authors think that the incidence of cervial cancer in Arab countries is lower than that in the Western countries due to the fact that muslim men are all circumcised, but it will be more likely that it is due to the widespread use of the squat tolilet where the women is forced to spread the thigs.

\section{Conclusions}

Most doctors are fixed on evidence based medicine, often forgetting to take into consideration some very simple and logical solutions to the problems. The aim of this paper is to encourage the colleagues to start research about it, because until today no one mentions this specific female modern life style problem. It is well known that some physical, chemical and biological agents have carcinogenic effects. The exposure to these agents can be intentional, like in smoking cigarettes, or unintentional, like the exposure to color solvents in dye workers. The exposure to HRHPV infection is obviously difficult to avoid, but there can be a simple way to significantly reduce the likelihood for a persistent HRHPV infection, by eliminating conditions suitable for growth of the virus.

Based upon the foregoing, the conclusion might be that an appropriate behavioral change in women could reduce the risk for cervix cancer. It means that young girls should be educated for correct micturition, with their thighs spread and take more often a bath in tube, or perform a flush of the vaginawith a mild disinfectant solution, i.e. an neutral intimate shampoo. This could be an important step forwards in cervical cancer prevention.

\section{Conflicts of Interest Statement}

None declared.

\section{References}

[1] Corusic, A., Skrgatic, L., Mahovlic, V., Mandic, V., Planinic, P. and Karadza, M. (2010) Cervical Cancer as a Public Health Issue-What Next? Collegium Antropologicum, 34, 301-307.

[2] Snijders, P.J., Steenbergen, R.D., Heideman, D.A. and Meijer, C.J. (2006) HPV-Mediated Cervical Carcinogenesis: Concepts and Clinical Implications. The Journal of Pathology, 208, 152-164. http://dx.doi.org/10.1002/path.1866

[3] Mougin, C., Dalstein, V., Pretet, J.L., et al. (2001) Epidemiology of Cervical Papillomavirus Infections. Recent Knowledge. La Presse Medicale, 30, 1017-1023.

[4] Adams, M., Borysiewicz, L., Fiander, A., et al. (2001) Clinical Studies of Human Papillomavirus Vaccines in PreInvasiveand Invasive Cancer. Vaccine, 19, 2549-2556. http://dx.doi.org/10.1016/S0264-410X(00)00488-6

[5] Hakama, M. and Louhivuori, K. (1988) A Screening Programme for Cervical Cancer That Worked. Cancer Surveillance, 7, 403-416.

[6] Deacon, J.M., Evans, C.D., Yule, R., et al. (2000) Sexual Behaviour and Smoking as Determinants of Cervical HPV Infection and of CIN 3 among Those Infected: A Case-Control Study Nested within the Manchester Cohort. British Journal of Cancer, 88, 1565-1572. http://dx.doi.org/10.1054/bjoc.2000.1523

[7] Muñoz, N., Franceschi, S., Bosetti, C., Moreno, V., Herrero, R., Smith, J.S., Shah, K.V., Meijer, C.J. and Bosch, F.X. (2002) International Agency for Research on Cancer. Multicentric CervicalCancer Study Group. Role of Parity and Human Papillomavirus in Cervical Cancer: The IARC Multicentric Case-Control Study. The Lancet, 359, $1093-1101$. http://dx.doi.org/10.1016/S0140-6736(02)08151-5

[8] Insinga, R.P., Dasbach, E.J. and Elbasha, E.H. (2005) Assessing the Annual Economic Burden of Preventing and Treating Anogenital Human Papillomavirus-Related Disease in the US: Analytic Framework and Review of the Literature. Pharmacoeconomics, 23, 1107-1122. http://dx.doi.org/10.2165/00019053-200523110-00004 
[9] Nowakowski, A.M. and Kotarski, J. (2011) Risk Factors of Cervical Cancer and Possibilities of Primary Prevention. Przeglad Epidemiologiczny, 65, 81-88.

[10] Wattleworth, R. (2011) Human Papillomavirus Infection and the Links to Penile and Cervical Cancer. The Journal of the American Osteopathic Association, 111, 3-10. 